\title{
A MORAL E A ÉTICA ROMANA ASSIMILADA PELOS POSTULADOS JURÍDICOS ${ }^{1}$
}

PELICANO, Henrique José Rosa²

ATIQUE, Wadi ${ }^{3}$

RESUMO: A história e a cultura italiana, sob muitos aspectos, tem exercido forte influência sobre muitas sociedades ao longo dos eventos da civilização. O objetivo de nosso texto, não é outro, se não o de pontuar alguns fragmentos desta riquíssima narrativa, fazendo-a se aproximar, o quanto possível, dos fundamentos que instituem o Direito no Brasil. Neste sentido, a metodologia que julgamos mais apta para dar conta de atender a esta demanda, foi a da revisão bibliográfica em acervos físicos e digitais. Justifica a realização de um trabalho como o nosso, a necessidade de se construir um volume de conhecimento que dê conta de sumariar e conduzir os interessados nos estudos sobre Direito Romano ou em História da Itália. Como resultados de nossas leituras, colocamos em destaque, o fato de que muitos aspectos comportamentais, de pensamento, de cultura e da moral romana, deram substância efetiva aos postulados do Direito que, ainda hoje, são praticados e respeitados em muitos ordenamentos jurídicos dispersos pelo mundo, inclusive, no Brasil.

PALAVRAS-CHAVE: História do Direito, Direito Romano, ética e moral

ABSTRACT: Italian history and culture, in many ways, has had a strong influence on many societies throughout the events of civilization. The purpose of our text is not different, it does not indicate some fragments of this very rich narrative, bringing it as close as possible to the foundations that establish the Law in Brazil. In this sense, the methodology that we think is best suited to meet this demand, was the bibliographic review on physical and digital collections. It justifies the realization of a work like ours, the need to build a volume of knowledge that can summarize and guide those interested in studies on Roman Law or in the History of Italy. As a result of our readings, we highlight the fact that many aspects of behavior, thought, culture and Roman morality, gave effective substance to the postulates of Law that, even today, are practiced and respected in many legal systems dispersed by the even in Brazil.

KEYWORDS: History of Law, Roman Law, ethics and morals

\footnotetext{
${ }^{1}$ Artigo derivado de Trabalho de Conclusão de Curso, apresentado ao Centro Universitário de Rio Preto UNIRP (2018), por ocasião da Graduação no Curso de Bacharelado em Direito, escrito e defendido em banca de avaliação, sob a orientação do Prof. Wadi Atique. Do TCC, intitulado "O DIREITO ITALIANO: HISTÓRIA, INFLUÊNCIA E LEGADO”, originaram-se este e outro Artigo, de mesmo nome, incluso na Revista AKEDIA - Versões, Negligências e Outros Mundos, vol. 9, $1^{\circ}$ sem. de 2020.

2 Bacharel em Direito / UNIRP (2019). Especializando em Direito Ambiental. Graduando em História. Bacharel em Ciências Biológicas pela UNESP, Universidade Estadual Paulista Júlio de Mesquita Filho, campus de São José do Rio Preto, IBILCE (2012).

${ }^{3}$ Docente na Sociedade Rio-pretense de Ensino e Educação / UNIRP.
} 


\section{INTRODUÇÃO}

A pesquisa ora apresentada se debruça em entender e descrever parte dos vieses de uma herança cultural que, oriunda de Roma, singrou os mares da História e se mantém ativa na memória de muitos povos do mundo, rompendo as fronteiras do tempo cronológico e do espaço geográfico. A relevância de estudarmos suas contribuições reside ainda na ideia de que seus feitos são tão amplos, que deixaram legados que vão da engenharia à arquitetura, da política ao militarismo e da religião ao Direito, e, claro, neste último cenário, em suma, é que repousa o foco principal de nossa escrita.

Tal como a língua latina, o Direito Romano sobrevive imanente em muitos postulados jurídicos nacionais e internacionais. Não somente no âmbito de estar pulverizado e influente em outras nações, mas atuante, o que é condição que, per se, já balizaria a realização de um estudo como o nosso.

Portanto, como primeiro dos resultados possíveis de nossa investigação, destaca-se o fato de que não nos resta dúvida de que a existência de argumentos de um Direito, assim, tão enraizado, com lastros há cerca de mais dois milênios, chega a ser surpreendente e meritório que ainda esteja fluente (em alguns institutos é praticamente intacto), o que, no mínimo, já é de uma beleza histórica indescritível.

A península Itálica, atual República Italiana, conservou muito do que era costume e também dos princípios da Roma Antiga. Desde o exercício de relações afetuosas, a partir do cumprimento de mãos, até a extrema e admirável preocupação com o passado e com a memória do próprio povo, a Itália continua sendo um verdadeiro museu sociocultural a céu aberto e, sob o ponto de vista antropológico, também um museu sociológico vivo.

O Direito Italiano, aqui definido como uma expressão para representar esse compêndio de atributos atinentes ao Direito Civil atual, Direito Canônico e ao Direito Romano, é um dos pilares que sustentam e nutrem o Direito pátrio no Brasil. 
Para que se analise, enfim, a abrangência dos princípios e costumes romanos, marco inicial dos "direitos da Itália", centramos nossos objetivos aqui na importância de se entender como a moral e a ética eram seguidas e cunhadas pelos antigos romanos. Conhecer como pensavam - e ainda pensam - os habitantes da "Velha Bota" é entender como se originou o Direito Romano; verdadeira matéria-prima e ponto de partida para a elaboração do corpus jurídico.

Neste sentido, evidenciaram-se outros resultados do estudo, tais como a percepção dos princípios e costumes que foram paulatinamente surgindo ao ritmo em que a História de Roma era traçada. Uma profusão de culturas e povos, pensamentos divergentes e convergentes, conquistas, guerras, traições, emboscadas, casamentos, religiões, organizações políticas. Isso tudo, em meio ao concurso de uma série de reis romanos que começavam a instituir formalmente um Direito Romano Primitivo, mas já de importância incalculável.

Países como os Estados Unidos, Argentina e Brasil receberam milhares de italianos nos períodos pós I e II Guerras Mundiais. Consequentemente, a cultura romana foi não apenas incorporada, mas também alteradora da cultura pré-existente nos países de chegada deste contingente populacional, de forma que se pode até pensar em muitas "Itálias fora da Itália".

Conclusivamente, acenamos que outro elemento que nos chamou bastante a atenção nesta varredura bibliográfica sobre a Roma Antiga e seus postulados éticos e a instituição do Direito, é o de que durante as grandes migrações, os italianos levaram muito mais do que apenas mão-de-obra, mas sim toda essa riqueza social e cultural imensurável. Ou seja, é fato que os aspectos histórico-culturais foram levados da Itália para outras localidades e, do mesmo modo, vemos que não teria como ser diferente com os princípios e costumes norteadores do Direito Italiano e seu estabelecimento entre nós. 


\section{DOS ROMANOS E DA ATUAL ITÁLIA}

A famosa águia romana, símbolo do Império Romano é bastante conhecida e comumente acompanhada pela sigla SPQR - Senatvs Popvlvsqve Romanvs (O Senado e o Povo Romano).

Os italianos costumam brincar com a expressão dizendo que a sigla se trata de "Sono Pazzi Questi Romani!" (São loucos esses romanos!). Obelix, personagem de Uderzo e Goscinny, costuma dizer para seu amigo Asterix sua bem conhecida frase: "Esses romanos são loucos!".

Essa brincadeira está pautada na fama histórica dos romanos de terem realizado feitos e ações que provavelmente deixaram - e ainda deixam - muita gente pasmada.

A origem mítica da cidade de Roma já mostra um povo de essência bastante bélica, vez que tal como ocorrem em algumas espécies de tubarões, numa analogia grosseira, irmão mata irmão pela primazia de sucesso.

O fratricídio entre Rômulo e Remo pode ser comparado com aquele de Caim e Abel, bem como com outras histórias (ou estórias) retiradas de diversas culturas. Esse critério entre irmãos, assim, não é algo restrito aos romanos, mas talvez da espécie humana. Poder-se-ia dizer, por isso, que a disputa e a competição também compeliram a humanidade para o progresso e evolução, biológica, social, política, esportiva, bélica etc.

Embora fascinante, há de se iluminar o fato de quem nem tudo na Roma Antiga é exatamente belo. Aqui, nos reportamos ao episódio do sequestro de mulheres sabinas ${ }^{4}$. Embora restrita a debates históricos sobre a veracidade histórica ou apenas mítica deste enredo, é inegável que há a possibilidade da disseminação do emprego do estupro nos primórdios da civilização romana a partir da instalação deste evento no inconsciente coletivo. Mas, infelizmente, também se trata de uma prática verificada na história de outras culturas.

\footnotetext{
${ }^{4}$ Segundo os historiadores Lívio e Plutarco, Rômulo propôs um festival para Netuno Equestre, convidando os povos vizinhos, tais como os Antemnos, os Crustumerinos, os Cenicenses e os Sabinos. Durante o festival, Rômulo ordenou aos romanos para que raptassem as mulheres sabinas (PLUTARCO. Vida de Rômulo. TITO LÍVIO, Ad Urbe Condita).
} 
No entanto, essa fama de instituir histórias entremeadas com tons de terror, asco, não começou sem justificativa. Tomemos por exemplo, os imperadores de Roma. Heliogábalo se castrou em público. Nero ordenou a morte da própria mãe, bem como ateou fogo em Roma. Claudius, por sua vez, era um incentivador da tortura e da violência. Já, Calígula, agenciava orgias, mortes e promoveu seu cavalo, Incitatus (Impetuoso), ao cargo de Cônsul, comandando um exército.

\section{O PRAGMATISMO ROMANO E SEUS INSTITUTOS}

Certamente, observa-se que o povo romano, então, era uma sociedade propensa às praticidades. Assim, diferentemente dos filósofos e matemáticos gregos, ainda que alguns destes tenham nascido na península itálica, pode-se inferir que a principal contribuição que Roma promoveu no campo das ciências exatas foi no ramo das engenharias.

Isso não quer dizer que os romanos não conhecessem o arcabouço teórico, até porque sem o mesmo suporte não haveria o resultado fático. Ocorre, portanto, que a tendência era priorizar justamente aquilo de mais palpável e "útil". Os romanos certamente prefeririam usar suas mentes e tempo para calcular como uma ponte iria ser construída do que por questões como a origem do número zero, desconhecido por um bom tempo.

Com a Itália atual, claro que esses conceitos foram enriquecidos. Bastaria o nome de Galileo Galilei, Leonardo da Vinci para darmos a devida comprovação ao que alegamos, mas, ainda sim, seria injusto deixar de mencionar outros brilhantes como Enrico Fermi, Girolamo Cardamo, Amedeo Avogadro, Evangelista Torricelli, Leonardo Fibonacci e outros tantos.

Da mesma maneira, os conflitos que foram surgindo naturalmente entre pessoas (hoje jurídicas ou físicas) seriam muito mais facilmente resolvidos, se houvesse algo predeterminado para dizer o que fazer sobre aquele caso.

O indivíduo cometera definida ação, logo conforme os moldes de uma lei, sua punição ou absolvição seria dada. Isso alavancava e promovia 
celeridade aos casos, de forma que vários delitos já estariam ali previstos. A evolução do Direito se pautou justamente em ampliar as chances de defesa, de procedimentos, de recursos etc., mas conforme já escrito, há partes quase sem alteração e outras literalmente intactas herdadas do Direito Romano.

Ou seja, impulsionava-se a justiça de forma prática. Novamente, o Direito é um cardápio e um guia consultivo para os operadores da lei. $\mathrm{O}$ advogado, magistrado ou qualquer outro que estude e trabalhe com as leis, deve ter em mente a teoria, no entanto, ser o mais objetivo, claro, conciso e direto possível, noutras palavras praticidades.

Esse legado é talvez o maior que os romanos ofereceram ao mundo, em especial aos italianos. O Direito Italiano é, como se espera, bastante enraizado nas diretrizes do Direito Romano, além de que o Direito Canônico foi cunhado com as bases aqui já descritas.

O povo italiano manteve muito desse comportamento, desde pequenas coisas do dia-a-dia até questões mais sérias. $O$ enriquecimento cultural adquirido pelo Renascimento, por exemplo, trouxe inovações na Arquitetura, sempre em destaque do povo da Velha Bota.

Outro dos institutos culturais de Roma, especialmente na pessoa de Luca Pacioli, deriva a Contabilidade. Da Itália, então, ela se firma, de forma que também se trata de uma ciência bastante aplicada para sanar questões que demandam controle, celeridade e arquivamento.

$\mathrm{Na}$ mesma ordem de contribuições, a ritualística imensa da Igreja Católica Romana também sofreu essa influência. De forma análoga, outrora, cada "pecado" exigiria uma determinada oração e numa quantidade dela a ser dita pelo Presbítero. As missas, em Latim, também mostram uma forma de primar pela forma em que se celebra o atingimento do conteúdo, numa esfera mais política, hoje praticamente em desuso.

Os vizinhos mais ao Norte da Itália, também famosos por serem excelentes guerreiros, a ponto de sua Terra receber o nome de Deustschland ("Terra das Lanças") se desenvolveram de forma distinta, justamente pelo 
motivo da Principiologia sociocultural deles ser diferente. Ainda assim, o Direito Alemão também é muito influente, assim como outras áreas do conhecimento.

Aliás, os alemães e suas linhagens talvez sejam o povo que mais descobertas e legados científicos tenham deixado, a ponto de serem conhecidos como "Terra dos Pensadores", e.g., Johannes Carl Friedrich Gauss, Johannes Sebastian Bach, Gottfried Leibniz, Johann Wolfgang van Goethe, Albert Einstein e a estes seguiria uma lista imensa de nomes.

Importante também ressaltar que Martinho Lutero rompera com a Igreja Católica Apostólica Romana, na Reforma Protestante. Lutero era alemão e se preocupou em verificar justamente questões de conteúdo e análise que não eram foco de outros povos.

Desta forma, pode-se traçar um paralelo entre uma vocação mais prática dos italianos, os quais também mantém uma forte cultura de apreço e valor pela família. Permanecem mais reunidos, são mais expansivos em seus sentimentos, unidos pelo país, mas desunidos pelas regiões (movimentos de separação, especialmente no Norte da Itália não faltam).

Esses valores são herdados dos princípios que versam sobre como o romano de virtude deveria se comportar, quais as condutas a serem seguidas e bem-vistas, enquanto que uma união vista externamente, mas bastante diferente, vista de dentro, já ocorria desde a união entre romanos, sabinos e etruscos. O próprio Inno Italiano corrobora o chamado pela união.

\section{A URBE ROMANA: COSTUMES E LEIS PARA O MUNDO}

Os reis da Roma Monárquica alternaram-se pela origem étnica e o que se verificou, foi justamente os avanços mais destacados nas áreas que mais eram compatíveis com a identidade de seu povo. A Itália atual não pode ser igualada com a vocação bélica dos romanos, pois que suas participações em guerras não apresentam elevados índices de sucesso e também há uma mancha que se Ihes impõe, em função da participação e pelo apoio ao Eixo, durante a Segunda Guerra Mundial, ainda que com participação modesta. 
Benito Mussolini levaria isso ao extremo, manchando a História da Itália com seu fascismo e apoio à Alemanha, no Eixo.

Esse declínio se deu a partir da própria queda do Império Romano, especialmente do Ocidente, quando a Itália passou a ser palco de disputa entre diversos povos. Alguns mesmo dentro da própria península, outros das regiões proximais. Neste período, as diferenças se intensificaram e a Itália passou a sofrer influências de povos como França e Espanha, enriquecendo e ao mesmo tempo tornando as culturas de cada região mais distantes entre si.

Vários Reinos, Repúblicas e Estados foram fundados e extintos num país de dimensões físicas bem pequenas. Isso alimentou essas diferenças, a ponto do regionalismo na Itália ser espantoso: vilas que distam menos de 10 $\mathrm{km}$ entre si falam dialetos totalmente diferentes umas das outras.

O enfraquecimento da identidade cultural dos italianos preocupara até mesmo Maquiavel. Contudo, Garibaldi, Manzzini, homenageados no Janículo em Roma, foram heróis nacionais que ajudaram o Rei Vittorio Emmanuelle a chegar à Unificação Italiana. O monumento Vittoriano é belíssimo e considerado o mais importante monumento da Itália.

Ainda que todos esses processos históricos tenham ocorrido na Itália, é de se admirar que o Direito tenha sobrevivido juntamente com a conservação do Latim e de instituições que surgiram há milênios. Boa parte disso provém da forma e da maneira de pensar do povo italiano. O qual se apresenta sempre de forma bastante determinadas e protetiva aos seus costumes, aliás, sendo motivo de supremo orgulho.

Desde Roma que não se usa a mão esquerda para servir o vinho, por exemplo, e o italiano considera deselegante, quase um insulto, quando isso ocorre. Essa herança provém de que a mão esquerda era utilizada para os romanos se limparem após suas necessidades fisiológicas. A coletividade era promovida não somente nas Cúrias, Fórum e no Senado. O coletivismo dos romanos se dava também através de banhos termais, onde, além da intenção de aprimorar a saúde, eram debatidas questões diversas, desde políticas, até jogos. Um exemplo claro dessa prática romana é o Termas de Caracala, em Roma, onde há locais em que até mesmo o piso está bem conservado. 
Outro aspecto importante era de que as leis deveriam ser obrigatoriamente escritas, pois, assim, não iriam se perder no tempo e ao vento. O princípio "Verba Volant" (palavras voam) foi também utilizado por Leonardo da Vinci, para explicar que, dentre tantas áreas do conhecimento pelas quais se interessou, a música foi uma daquelas que Leonardo deixara com menor prioridade, por alegar que seria uma forma de arte que se perderia ao vento. Consequentemente, por meio dessa postura protecionista e "desconfiada", a burocracia em países que sofreram influências romanas é bastante elevada.

\section{PRINCÍPIOS DO DIREITO BRASILEIRO}

A preocupação com a natureza documental também se faz muito forte no ordenamento jurídico pátrio. O Direito Civil da República Federativa do Brasil é pródigo de uma herança bastante forte dos antigos romanos, a qual continua pulsante e atuante no cotidiano de milhões de pessoas. Quanto a sua origem, esse nosso ordenamento é irmão de vários outros arcabouços do Direito, ainda que precipuamente advenha do Direito Italiano.

A relação, dentro do âmbito do Direito Internacional entre a Itália e o Brasil é bastante amistosa. Essa intensificação se deu após o recebimento brasileiro de milhares de italianos imigrantes, os quais fundaram suas colônias principalmente na Argentina e no Brasil, no continente Sul-Americano.

Essa influência gerou uma comunidade imensa de italianos e italófilos, os quais constituíram bairros consagradamente reconhecidos como uma reserva de "italianismo". É o caso da Mooca, Brás, Bexiga, Bela Vista e Barra Funda, em São Paulo. Locais onde várias festas são ainda celebradas, tais como aquelas de Agosto em homenagem à Santa Maria Achiropita.

O interior de São Paulo e da região Sul do Brasil também foram vastamente povoados por italianos e seus costumes, os quais levaram não tão somente o sangue, mas também seus costumes e obviamente suas paixões, valores e princípios. Com os italianos, a culinária, a agricultura, os ofícios 
manuais e algumas ciências foram desenvolvidos no Brasil. Trouxeram também danças, festividades, jogos como a Briscola, Truco e a Scopa.

Com o mesmo coletivismo, fundaram a Sociedade Esportiva Palmeiras, após a fundação do Sport Club Corinthians Paulista, também com participação de italianos. O Palmeiras, outrora Palestra Itália, era assim denominado porque "Palestra", em italiano, é termo que se emprega para designar um "ginásio", mas também num âmbito maior, local onde pessoas possam se reunir para interação, lazer, cultura e também o esporte.

Nesse sentido, nasceram muitos clubes no Brasil, assim também intitulados de "Palestra": Como exemplo, em São José do Rio Preto, há o "Palestra Esporte Clube", originalmente, em sua constituição, denominado de "Palestra Itália Esporte Clube". Essa Principiologia cultural foi mantida e herdada por italianos, desde os romanos, e também enraizada no Brasil.

O fortalecimento da Igreja Católica Apostólica Romana, das instituições políticas, jurídicas e acadêmicas, foi imenso. Dioceses e Arquidioceses foram criadas e ampliadas após a chegada dos italianos, a culinária foi incalculavelmente enriquecida, os ofícios manuais com técnicas italianas, conhecidos pela sua excelência. Além do que, vários sobrenomes italianos estão presentes em instituições políticas ou judiciárias.

Emílio Garrastazu Médici, 28ํㅗ Presidente do Brasil, era filho de Italiano. Ao seu turno, Goiás, Porto Alegre, Campinas, Poços de Caldas, São Paulo são algumas das cidades que ganharam uma Universidade Pontifícia Católica - as renomadas PUCs. Dessa forma, os princípios de Honestere vivere, Dignitas, Fides, Gravitas, Mores Maiorum, Neminem Laedere, Pietas etc, foram instalados e corroborados à cultura brasileira. Tais princípios começaram sua germinação nos povos mais primitivos da formação de Roma, algo totalmente influente na constituição do povo italiano e de seus direitos.

Esses povos da Roma Antiga forneceram a matéria prima para a construção do Direito hoje utilizado em inúmeras nações, pois que os costumes e princípios antecederam a própria lex, sendo esta uma positivação destes combinada com "Verba Volant". 


\section{CONCLUSÃO}

A história da Itália, após a queda do Império Romano, certamente contribuiu para novas perspectivas do Direito Italiano e essa evolução também foi trazida ao Brasil pela comunidade italiana, especialmente por vênetos e calabreses. Ao lado disso, em nossas leituras, vimos que os contrastes morais, éticos, muito presentes nesta riquíssima história, pôs, lado a lado, a origem mítica de Roma. Este fato nos sugere a compreensão de Roma por meio de uma lenda ou uma releitura de sua / nossa realidade.

Do mesmo modo, os princípios morais e éticos que regem a população e seus reis, chefes e imperadores, denotam, dentre outras posturas, uma itensa busca pela praticidade, ainda que com um arcabouço teórico imenso.

Outro dado curioso, é o de que as diferenças entre os italianos nortistas e sulistas, muito desunidos entre si, os fazem aparecem unidos diante dos demais italianos: este é um legado comportamental que venceu o tempo, mas que foi incapaz de resolver as questões da política italiana atual.

Em termos geopolíticos mais amplos, a Itália é uma potência média, ainda hoje é influência modesta, de alcance apenas à região em que se situa, ainda que berço do Império que por séculos influenciou o mundo.

Adorados pela sua cultura e carisma, ao mesmo tempo temidos e evitados pela máfia de seu País, muitos são aqueles que se declaram descrentes da Itália, ao contrário dos italianos, orgulhosos do passado de seu Império Romano. Roma, portanto, já fora sinônimo de riqueza e força. Entretanto, contemporaneamente, são frequentemente derrotados em situações de conflitos e confrontos bélicos, a despeito de serem herdeiros do exército mais eficiente que pisou sobre a Terra, deixando grandes potências com cicatrizes nos joelhos, de tanto terem se curvado para Roma. "Ma davvero Sono Pazzi Questi Romani?".

Sem margem para dúvidas, nessas contradições que a História mostra, a única constância que se pode ter é da própria inconstância. Um ciclo de altos e baixos, vitórias e derrotas, apogeus e declínios. No entanto, no palco da vida, 
o Direito Romano se recusa bravamente a se entregar. Eis a maior vitória, ché Schiava di Roma, Iddio la creò!

Os princípios de virtude, honra, justiça, respeito ao próximo e outros que se passariam tranquilamente como princípios Cristãos e do homem de bem, princípios que seriam tão bem recebidos pelas nações afora, foram plantados, germinados e irrigados até os italianos atuais: principais sucessores do legado romano. Com a natural evolução humana (intrínseca e extrínseca) e consequente demanda para se regular as condições para uma vida o mais saudável e justa que o imaginário conceberia, o Direito foi ganhando força e forma. Claro, surgiu como uma real necessidade para tornar a vida não apenas mais coerente, mas possível.

Com a inteligência e praticidade dos romanos, iniciou-se maior preocupação na aplicação, hierarquização e organização deste Direito Primitivo. A eficiência foi tamanha que serviu de Norte e como bússola para milhões de pessoas, em diversos Estados, rompendo as barreiras do tempo.

Os italianos, bem como os demais povos latinos, também receberam muito da ética romana, isto é, de sua forma de pensar, agir, falar e se comportar. A Igreja Católica Apostólica Romana foi fortemente influenciada em sua estrutura com os ideais mais primitivistas da Velha Bota e, não por acaso, foi e Igreja Católica, a Igreja de maior influência na História, praticamente desbravadora de todas as demais denominações Cristãs.

Enfim, não tão somente com a Verba Volant ou com a letra da Lei e construiu o Direito Italiano, Direito da Itália, seja de Roma, Canônico ou da atual República, mas de toda a cultura, sociedade e pensamento italianos é que vieram as sementes germinadoras de toda a Lei, as quais ininterruptamente vêm dando frutos aos quatro cantos da Terra. 


\section{REFERÊNCIAS}

ADKINS, L. and Adkins, R. Dictionary of Roman Religion. Nova lorque: Oxford University Press, 2000.

APPUZO, Michael L.J. M.D. Gravitas, Severitas, Veritas, Virtus. Neurosurgery: August 2006, v. 59, issue 2, p. 219-221.

BARTOLONO, GILDA. The Villanovan Culture: at the beginning of Etruscan history. In: Turfa, Jean Maclntosh (ed.). The Etruscan World. Routledge, 2014.

BEARD, MARY. SPQR: Uma História da Roma Antiga. São Paulo: Editora Planeta, 2017.

BERGER, Adolph. Encyclopedic Dictionary of Roman Law. Filadélfia: The American Philosophical Society, 1991.

CARTWRIGHT, MARK. Etruscan Society. Ancient History Encyclopedia. https://www.ancient.eu/user/markzcartwright. Acesso em 17/09/2018, às 12:05 horas.

CÍCERO. De Natura Deorum. http://www.dominiopublico.gov.br/pesquisa/PesquisaObraForm.do?select_actio n\&co_autor $=174$. Acesso em 17/09/2018, às $11 \mathrm{~h}: 51 \mathrm{~min}$.

COARELLI Filippo. I Santuari, I fiumi, Gli Empori. XIII. Storia Einaudi dei Greci e dei Romani, 2008.

COLLINS, Willian et al. Collins Spanish Dictionary. Harper, 2006.

COLLINS, Willian et al. Collins Italian Dictionary. Harper, 2007.

CRETELLA, Júnior. Curso de Direito Romano - O direito romano e o direito civil brasileiro. 20ª Edição. Rio de Janeiro: Forense, 1997.

CRUZ, Sebastião. Jus Derectum (Directum). Coimbra, 1971. Apud FERRAZ Jr., T.S. Introdução ao Estudo do Direito. São Paulo: Atlas, 1988.

DA SILVA, Claudio Henrique Ribeiro. Direito Romano Arcaico - Parte III. 4.3. O Direito Secreto. Disponível em: www.ribeirodasilva.pro.br/direitoromanoarcaicoparte03-02.html. Acesso em 17/09/2018, às 11h:31min.

DE PLÁCIDO E SILVA. Vocabulário Jurídico. 31르 Edição. Rio de Janeiro: Editora Gen / Forense. 2014.

DINIZ, Maria Helena. Código Civil Anotado. São Paulo: Saraiva, 2003. Apud VIVIAN, Wilson A. B. Princípio Alterum non Laedere (Nenimen Laedere), dignidade humana e boa-fé. 2015. Disponível em: https://jus.com.br/artigos/35605/principio-alterum-non-laedere-neminemlaedere-dignidade-humana-e-boa-fe. Acesso em 17/09/2018, às 11h:33min. 

us/home.html. Acesso em 17/9/2018, às 11h:50min.

DOWDING, JANKA. The Elusive Etruscans: The Quest for the Origins of the Etruscan Civilization - Hirundo. The McGill Journal of Classical Studies, 20062007.

FESTO, Pompeu. Istituzioni di Diritto Romano. Tradução italiana.

GILBERT, John. Mitos e lendas da Roma Antiga. $2^{\text {a }}$ ed. São Paulo: Melhoramentos, 1978.

GIORDANI, Mário Curtis. Iniciação ao Direito Romano. 3" Edição. Editora Lumen Juris, 1996.

HOUAISS Antonio, Villar, Mauro de Salles. Houaiss, Dicionário de Língua Portuguesa. Editora Objetiva, 2009.

HUNTSMAN, Theresa. Etruscan Language and Inscriptions. In: The Metropolitan Museum of Art. Heilbrunn Timeline of Art History, 2000.

JUSTINIANO, Digest. 1.1.10. In: Watson, Alan (ed.). The Digest of Justinian. Philadelphia: U. Pennsylvania, 1985.

LAROUSSE. Petit Dictionnaire de Français. Larousse. 2004.

MATEUS. Evangelho segundo São Mateus - Bíblia Sagrada. Sociedade Bíblica do Brasil. Barueri: Edição Bilíngue Chinês - Português, 2012.

MAQUIAVEL, Nicolau. O Príncipe. Jardim dos Livros, 2008.

MARROU. As Escolas Romanas. In: História da Educação na Antiguidade. São Paulo: Herder, 1966.

NISHITANI, Yuko. Introdução à História do Direito Japonês. Revista Cadernos do Programa de Pós-Graduação em Direito. Universidade Federal do Rio Grande do Sul, 2003.

PACCHIONI. Diritto Romano - I. Apud PEIXOTO, José Carlos de Matos. Curso de Direito Romano. Tomo I: partes introdutórias e geral/José Carlos de Matos Peixoto. Rio de Janeiro: Renovar, 1997.

PEIXOTO, José Carlos de Matos. Curso de Direito Romano - Tomo I: partes introdutórias e geral. Rio de Janeiro: Renovar, 1997.

PLATÃO. Apologia de Sócrates. São Paulo: Nova Fronteira, 2017.

PLUTARCO. Vida de Rômulo. Domínio Público. Disponível em: http://www.dominiopublico.gov.br/pesquisa/PesquisaObraForm.do?select_actio n\&co_autor= 174. Acesso em 17/09/2018, às 11h:54min. 
PLUTARCO. Vida de Rômulo. Domínio Público. Disponível em: http://www.dominiopublico.gov.br/pesquisa/PesquisaObraForm.do?select_actio n\&co_autor $=174$. Acesso em 17/09/2018, às $11 \mathrm{~h}: 54 \mathrm{~min}$.

Vidas Paralelas Rômulo. Domínio Público. Disponível em:

http://www.dominiopublico.gov.br/pesquisa/PesquisaObraForm.do?select_actio n\&co_autor=174. Acesso em 17/09/2018, às 11h:54min.

POLÍBIO. Histórias. Domínio Público: https://www.researchgate.net/publication/310312128_Polibio_historia_pragmati ca_Livros_I

a_V_Traducao_introducao_e_notas_por_Breno_Battistin_Sebastiani_2016. Acesso em 17/09/2018, às $11 \mathrm{~h}: 59 \mathrm{~min}$.

PÖPPELMAN, Christa. Dicionário de Máximas e Expressões em Latim. Editora Escala: Traduzido por Ciro Mioranza, 2010.

SHINJITAI. Constituição do Japão, 1947.

TITO LÍVIO. Ab Urbe Condita Libris. Domínio Público: https://la.wikisource.org/wiki/Ab_Urbe_Condita. Acesso em 17/09/2018, às $11 \mathrm{~h}: 54 \mathrm{~min}$.

História de Roma. Domínio Público: https://la.wikisource.org/wiki/Ab_Urbe_Condita_\%E2\%80\%93_Periochae. Acesso em 17/09/2018, às $11 \mathrm{~h}: 54 \mathrm{~min}$.

VADE MECUM. 18ㄹ Edição, Saraiva, 2014.

WARD, A., Heichelheim, F., Yeo, C. A History of the Roman People. 4" Ed. Nova Jérsei: Prentice Hall, 2003. 